\title{
Molecular Pathogenesis of Middle East Respiratory Syndrome (MERS) Coronavirus
}

\author{
Arinjay Banerjee $^{1} \cdot$ Kaushal Baid ${ }^{2} \cdot$ Karen Mossman $^{1,2}$ \\ Published online: 5 July 2019 \\ (C) Springer Nature Switzerland AG 2019
}

\begin{abstract}
Purpose of Review Middle East respiratory syndrome coronavirus (MERS-CoV) emerged in 2012 and is listed in the World Health Organization's blueprint of priority diseases that need immediate research. Camels are reservoirs of this virus, and the virus spills over into humans through direct contact with camels. Human-to-human transmission and travel-associated cases have been identified as well. Limited studies have characterized the molecular pathogenesis of MERS-CoV. Most studies have used ectopic expression of viral proteins to characterize MERS-CoV and its ability to modulate antiviral responses in human cells. Studies with live virus are limited, largely due to the requirement of high containment laboratories. In this review, we have summarized current studies on MERS-CoV molecular pathogenesis and have mentioned some recent strategies that are being developed to control MERS-CoV infection.

Recent Findings Multiple antiviral molecules with the potential to inhibit MERS-CoV infection by disrupting virus-receptor interactions are being developed and tested. Although human vaccine candidates are still being developed, a candidate camel vaccine is being tested for efficacy. Combination of supportive treatment with interferon and antivirals is also being explored. Summary New antiviral molecules that inhibit MERS-CoV and host cell receptor interaction may become available in the future. Additional studies are required to identify and characterize the pathogenesis of MERS-CoV EMC/2012 and other circulating strains. An effective MERS-CoV vaccine, for humans and/or camels, along with an efficient combination antiviral therapy may help us prevent future MERS cases.
\end{abstract}

Keywords MERS · Coronavirus · Pathogenesis · Therapeutics

\section{Introduction}

Coronaviruses have historically been associated with low impact human disease, such as the common cold $[1,2]$. It was the sudden emergence of severe acute respiratory syndrome (SARS) coronavirus (CoV) in 2003 that made us aware of deadly versions of coronaviruses that can cause large

This article is part of Topical Collection on Virology

Karen Mossman

mossk@mcmaster.ca

1 Department of Pathology and Molecular Medicine, McMaster Immunology Research Center, Michael DeGroote Institute for Infectious Disease Research, McMaster University,

Hamilton, Ontario L8S 4L8, Canada

2 Department of Biochemistry and Biomedical Sciences, McMaster Immunology Research Center, Michael DeGroote Institute for Infectious Disease Research, McMaster University, Hamilton, Ontario L8S 4L8, Canada outbreaks associated with high mortality and global panic. SARS-CoV caused an outbreak that was deemed a pandemic and an international threat by the World Health Organization (WHO). A total of 8098 people were infected and of these 774 died [3]. Extensive epidemiological studies and wildlife surveillance revealed that SARS-CoV had originated in bats and somehow spread to civet cats. The virus is speculated to have later "jumped" from civet cats to humans [4-7]. This outbreak established the importance of wildlife (i.e., bats) in the emergence of highly pathogenic coronaviruses.

Middle East respiratory syndrome coronavirus (MERSCoV) emerged in September 2012 in the Kingdom of Saudi Arabia [8]. MERS-CoV causes a lower respiratory tract infection in humans with $35 \%$ mortality. Since its emergence, 2279 laboratory-confirmed cases have been identified in humans with 806 deaths. Twenty-seven countries have reported cases of MERS with many associated with travel. MERS-CoV has been listed on the WHO's blueprint of priority diseases needing immediate research. 
Currently, only supportive treatment exists for MERSCoV. MERS-CoV, like many other viruses, has evolved proteins that can effectively counteract human antiviral responses [9-11]. The sudden appearance of MERS, the high infectivity rate of the virus, and the need for a high containment level 3 lab for research have hindered progress in designing vaccines and therapeutics against this virus. Development of vaccine candidates is further complicated by the ability of coronaviruses to rapidly mutate and recombine [6]. Several quasispecies of the virus can be detected in camels [12], which are reservoirs of the virus, and it is extremely difficult to develop therapeutic strategies against a pathogen that can exist as several different variants.

The evolution of MERS-CoV is intriguing. It is speculated that MERS-CoV originally spilled over from bats to camels. Several MERS-like CoVs have been detected in bats [13-15, 16•, 17-19]. Current models propose that camels are reservoirs of the virus and are often the source of human infection [20-22]. Human-to-human transmission of MERS-CoV has also been documented [23]. In spite of these advances in our understanding of how the virus has evolved, there is a significant lack of knowledge about virus transmission dynamics and ecological and environmental factors that drive the emergence and evolution of MERS-CoV.

Several novel approaches are being currently developed to combat MERS-CoV, including small molecule inhibitors, monoclonal antibodies and vaccines. In this mini-review, we have discussed the pathogenesis of MERS-CoV and the role of various viral proteins in subverting antiviral responses in humans. We also discuss current approaches that are being developed and tested to control MERS-CoV replication and associated disease. Finally, we bring forward additional strategies to identify therapeutic targets and molecules to improve the outcome of MERS-CoV infections in humans.

\section{Coronavirus: Structure and Replication}

A mature $\mathrm{CoV}$ particle is spherical in shape and has a diameter of around $100 \mathrm{~nm}$ [24]. Virus particles have a protein coat, called the capsid, which protects the virus' genetic material. CoVs have an additional envelop of lipids surrounding the protein capsid. This layer is derived from portions of host cell membranes (phospholipids and proteins) but also include some viral glycoproteins. $\mathrm{CoV}$ virions contain four essential viral glycoproteins - spike $(\mathrm{S})$, membrane $(\mathrm{M})$, envelop $(\mathrm{E})$, and nucleocapsid $(\mathrm{N})$, all of which are encoded within the $3^{\prime}$ end of the viral genome [25]. S protein is club-shaped and located on the surface of the virion, giving $\mathrm{CoVs}$ a distinct appearance of a solar corona, hence the name - Coronaviruses. S protein is critical for the initial attachment of the virion to the host cell receptor, dipeptidyl peptidase 4 (DPP4) [26]. Recent studies have demonstrated that the spike protein can adapt to interact with DPP4 from different species of bats to enable cross-species entry and replication of MERS$\mathrm{CoV}[27 \bullet \bullet]$. The structure of $\mathrm{CoVs}$ is maintained by $\mathrm{M}$ protein while $\mathrm{E}$ protein facilitates the assembly and release of the virus. CoVs have helically symmetrical nucleocapsids and the only structural protein associated with the nucleocapsid is the $\mathrm{N}$ protein, which helps in the packaging of the virus genome (reviewed here $[25,28,29])$.

Viruses use host cell machinery to replicate (Fig. 1). CoVs have large, non-segmented positive-sense (+) RNA genomes of $30 \mathrm{~kb}$ and use their own RNA replicase enzymes to create copies of their genomes in the cytoplasm. CoVs complete their life cycle in 4 steps: (1) entry, (2) expression of the replicase protein, (3) replication and transcription of their genome, and (4) release of assembled progeny virions (reviewed here [25] and Fig. 1). CoVs interact through $\mathrm{S}$ protein with its cognate receptor on the surface of susceptible cells. The specificity of this interaction determines the host range and tissue tropism of CoVs. Many CoVs bind peptidases as their cognate receptor for entry, but the choice of receptor has been reported to vary across different $\mathrm{CoVs}$, for example, SARS-CoV uses an angiotensin-converting enzyme (ACE2) [30] and MERSCoV binds to DPP4 [26]. Subsequently, S protein undergoes acid-dependent proteolytic cleavage, resulting in the fusion of viral and cellular membranes and the release of the viral genome into the cytoplasm (reviewed here [29]).

Coronavirus genomes include a $5^{\prime}$ cap structure and a $3^{\prime}$ poly (A) tail, allowing them to act as messenger RNA (mRNA; positive-sense RNA) templates for translation of replicase polyproteins. The replicase gene encodes two large open reading frames (ORFs), repla and replab, which express two coterminal polyproteins, pp1a and pp1ab. These polyproteins are cleaved into individual non-structural proteins (Nsps). Nsp3 encodes a papain-like protease (PLpro) that cleaves Nsp1/2, Nsp2/3 and Nsp3/4 boundaries. Serine-type protease, also known as main protease (Mpro), which is encoded by Nsp5, cleaves the polyproteins into remaining Nsps. Nsps facilitate viral RNA synthesis, for example, Nsp12 encodes RNAdependent RNA polymerase (RdRp). The formation of a replicase-transcriptase complex (RTC) containing Nsps initiates viral RNA synthesis. The RTC complex localizes to modified intracellular membranes which are derived from the rough endoplasmic reticulum (ER) and initiates the production of negative-sense RNAs through both replication and transcription. Full-length copies of $\mathrm{CoV}$ negative-sense RNA genomes serve as a template to synthesize full-length positive-sense RNA genomes that eventually get packaged into new virions. CoVs utilize discontinuous transcription to generate a subset of sub-genomic negative-sense RNAs, including those encoding structural proteins [31]. Varying lengths of the $3^{\prime}$ end of the genome is combined with the $5^{\prime}$ leader sequence to make subgenomic negative-sense RNAs. These sub-genomic negativesense RNAs are then transcribed into sub-genomic positivesense mRNAs for translation. 


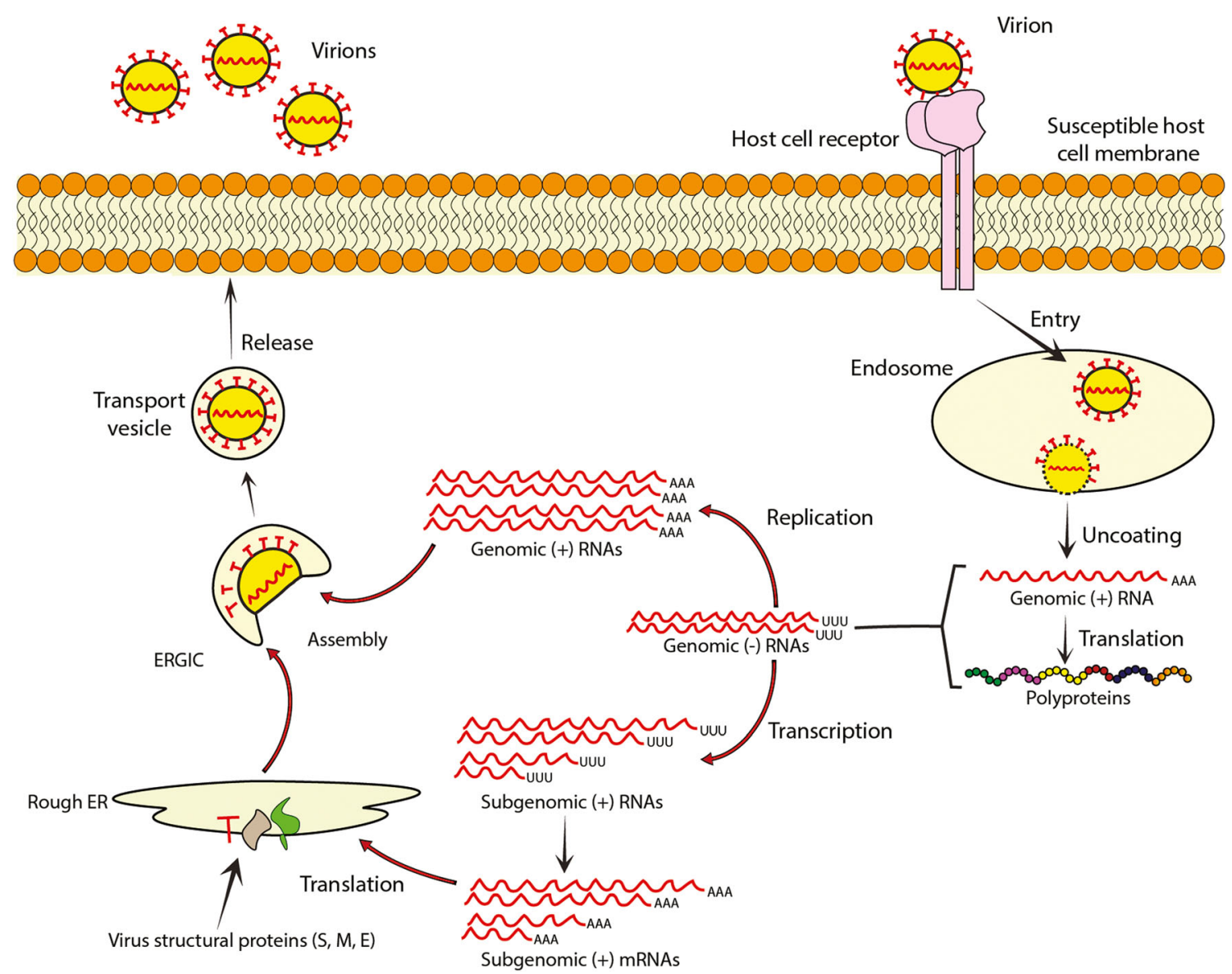

Fig. 1 MERS-CoV replication. MERS-CoV interacts with cellular DPP4 receptor to enter permissive cells. Inside the cell, the virus capsid disintegrates in endosomal compartments to release the positive $(+)$ sense genome in the cytoplasm. The $5^{\prime}$ end of the $(+)$ sense genome is translated to make replicase proteins, which enable transcription and replication of the genome. The (+) sense genome is transcribed to make $(-)$ sense full-length genome, which acts as a template for the synthesis of full-length (+) sense genome. (-) sense full-length genome is also used as a template to make sub-genomic (+) sense RNAs of varying lengths, which are transcribed to $(+)$ sense mRNAs. These mRNAs are translated to make several structural and accessory proteins in the endoplasmic reticulum. The genomic (+) sense RNA and the proteins come together to form a new virion in the endoplasmic reticulum (ER)Golgi intermediate compartment (ERGIC). The new virions are released through secretory vesicles

The viral structural proteins, such as S, E, and M, are translated from sub-genomic positive-sense mRNAs. The structural proteins are inserted into the endoplasmic reticulum-Golgi intermediate compartment (ERGIC). The viral genomes, encapsidated by $\mathrm{N}$ protein, bud into ERGIC containing the structural proteins for assembly. The newly assembled mature virions are then transported to the cell surface in vesicles and are released from the infected cell by exocytosis. The genome organization, replication and associated replicasetranscriptase proteins of murine hepatitis virus (MHV) have been extensively studied [32]. All identified coronaviruses use a similar replication strategy (reviewed here [25, 29]).

\section{Pathogenesis of MERS-CoV}

Pathological changes in a MERS-CoV infected patient have been studied with the help of a single research-oriented autopsy. The pathology in this fatal case primarily included exudated diffuse alveolar damage with hyaline membranes, pulmonary edema, type 2 pneumocyte hyperplasia, interstitial pneumonia that was predominantly lymphocytic, and multinucleate syncytial cells $[33,34]$.

Several studies have characterized MERS-CoV in cell lines and animal models. Like other viruses, MERS-CoV has evolved strategies to evade innate antiviral responses. The ability of the virus to suppress antiviral responses [11] and promote an exaggerated inflammatory response [35••] contributes to its pathogenesis. As described above, MERS$\mathrm{CoV}$ is made up of several structural, non-structural, and accessory proteins. MERS-CoV accessory proteins are dispensable for virus replication in tissue culture [36] but play an important role in modulating the host's antiviral defensive responses. Human and most mammalian cells have evolved evolutionarily conserved molecules (pattern recognition receptors or PRRs) that can detect conserved structures in 


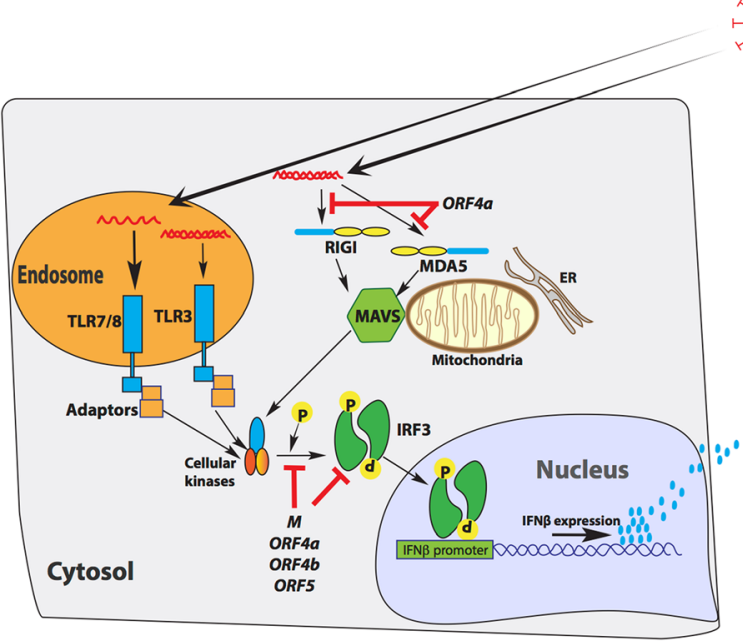

Fig. 2 MERS-CoV inhibits innate antiviral signaling. Mammalian cells have evolved conserved pathogen sensing molecules called pattern recognition receptors (PRRs). When a coronavirus, such as MERS$\mathrm{CoV}$, infects a human cell, the virus produces dsRNA as replication and transcription intermediates. dsRNA stimulates cellular sensors of viral nucleic acid such as TLR3, RIGI, and MDA5. These sensors, through adaptor proteins and cellular kinases (TBK1 and $\mathrm{IKK} \varepsilon$ ), activate interferon regulatory factor 3 (IRF3). Activated IRF3 molecules form
MERS-COV

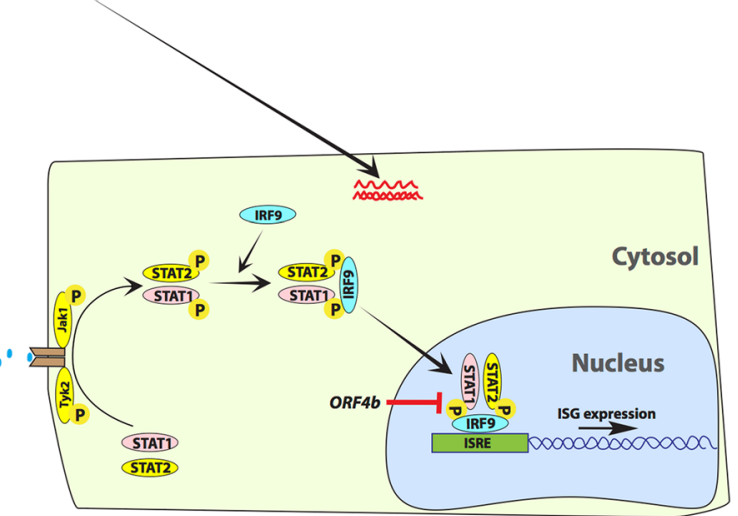

homodimers and translocate to the nucleus of the infected cell to induce the expression of type I IFNs (IFN $\alpha$ and IFN $\beta$ ). IFNs then bind to IFN $\alpha / \beta$ receptor (IFNAR) to stimulate the Jak/Stat pathway, which in turn induces the expression of antiviral interferon-stimulated genes (ISGs). ISGs protect cells from subsequent virus replication and associated cell damage. MERS-CoV proteins $\mathrm{M}$ and ORFs $4 \mathrm{a}, 4 \mathrm{~b}$, and 5 (depicted in italics) have evolved different strategies to inhibit the expression of interferon and ISGs. ER = endoplasmic reticulum

have sensed viral nucleic acid, the cells activate kinases such as TANK-binding kinase 1 (TBK1) and inhibitor of nuclear factor kappa-B kinase subunit epsilon (IKKe), which phosphorylate IRF3. Phosphorylated IRF3 forms dimers in the cytoplasm and localizes to the nucleus of the cells to initiate the expression of IFNs. MERS-CoV ORFs $4 \mathrm{a}, 4 \mathrm{~b}, 5$, and protein $\mathrm{M}$ inhibit kinase-mediated phosphorylation of IRF3 (Fig. 2). Ectopic expression of these proteins inhibits nuclear localization of IRF3 in human cells and downstream antiviral signaling in response to virus infection and synthetic dsRNA (polyI:C) stimulation $[10,11]$. Although the cellular interacting partners of all MERS-CoV viral proteins have not been identified, $M$ protein has been shown to inactivate TBK1-mediated phosphorylation of IRF3 by disrupting TRAF3-TBK1 association [42••]. MERS-CoV ORF 4b also inhibits nuclear factor kappa-light-chain-enhancer of activated B cell (NFKB)-dependent antiviral responses by abrogating nuclear import of signal transducer and activator of transcription 1 (STAT1) [43•] (Fig. 2).

In addition to accessory proteins, Nsps that are generated from the polyproteins ppla and pplab also play a role in modulating host processes. MERS-CoV Nsp1 selectively targets mRNAs that are generated in the nucleus and transported to the cytoplasm (cellular mRNA) for translation inhibition and mRNA degradation. Nsp1 spares mRNAs that are introduced directly in the cytoplasm or virus-like mRNAs that originate in the cytoplasm [44]. Thus Nsp1 inhibits cellular processes while promoting viral replication. 
There are limited studies with MERS-CoV, largely due to containment requirements. The modulation of adaptive immune responses by MERS-CoV has not been extensively studied, and cytokine responses in infected dendritic cells, macrophages, and other white blood cells have not been fully explored. In one study, antibody-mediated responses or seroconversion was observed in individuals that developed an asymptomatic infection with MERS-CoV. Patients that seroconverted at later time points developed pneumonia with or without respiratory failure. Although the rate of seroconversion increased with disease severity, $75 \%$ of the deceased MERS-CoV infected patients who developed pneumonia did not seroconvert [45]. Another study by Choi et al. demonstrated the absence of neutralizing antibodies one year after successful treatment of MERS-CoV infected patients who had developed mild pneumonia [46]. Their observation is consistent with the previous study where disease severity correlated with seroconversion. The inability to produce long-term neutralizing antibodies would put these individuals at risk for re-infection with MERS-CoV in the future. This possibility needs to be monitored and studied. These observations warrant further investigations on the ability of MERS-CoV to modulate humoral responses in patients.

The role of $\mathrm{T}$ cells in MERS-CoV infections has been recently reported. Zhao et al. analyzed antibody and $\mathrm{T}$ cell responses in peripheral blood mononuclear cells (PBMCs) and sera from twenty-one MERS survivors. The authors identified that patients with higher antibody and CD4+ T cell responses had longer intensive care unit stays and demonstrated prolonged virus shedding. In the same study, MERS survivors with undetectable MERS-CoV-specific antibody responses mounted CD8+ T cell responses [47]. This observation adds more detail to previous studies where neutralizing antibody levels were not detected in MERS survivors and disease severity correlated with seroconversion $[45,46]$. These observations raise an important question: can MERS-CoV infection be augmented by the presence of antibodies? MERS-CoV can infect and propagate in macrophages. MERS-CoV Nsp15 is an endoribonuclease, and it is speculated to suppress the activation of dsRNA sensors in infected cells, such as macrophages. Although the mechanism of action for Nsp15 is not known, Nsp15 mutant MERS-CoV displays significant dispersal of dsRNA associated with replication complexes relative to wild-type virus [48]. Since macrophages display Fc receptors that bind to the Fc portion of antibodies [49], it is of interest to identify if antibodies bound to MERS$\mathrm{CoV}$ can enhance virus uptake by macrophages and subsequent virus replication. In addition, the replication potential of MERS-CoV in other Fc receptor-bearing immune cells needs to be explored as well.

\section{Current Approaches to Tackle MERS-CoV}

There are currently no approved treatment or vaccine for MERS-CoV, but different approaches are being tested and developed to inhibit virus replication with promising preliminary data. These approaches have been extensively reviewed in recent reviews [50-52]. We mention broad strategies that are currently being discovered to orient readers to the possibilities of future treatment and preventative options.

The most commonly studied strategy is the inhibition of virus entry in human cells (Fig. 3). As previously mentioned, MERS-CoV binds to the human receptor DPP4 via its receptor-binding domain (RBD) in the spike protein. Monoclonal antibodies against the RBD and the receptorbinding motif within the RBD are being developed to inhibit this interaction (reviewed here [51]). Small molecules capable of disrupting the interaction between MERS-CoV spike protein and DPP4 are also being developed and tested (reviewed here [51]). MERS-CoV entry is accomplished through the fusion of the virus and cellular membranes that is mediated by the $\mathrm{S} 2$ region of the virus spike protein [53]. Inhibitory peptides targeting the $\mathrm{S} 2$ region of the spike protein to prevent fusion, and thus, entry of the virus are also being developed [52].

Current studies have focused on disrupting the interaction between MERS-CoV spike protein and the cellular DPP4 receptor. The recent discovery of an attachment factor, membrane-associated $78-\mathrm{kDa}$ glucose-regulated protein (GRP78), that augments MERS-CoV entry [54] further complicates this approach. There is a need to identify and target additional interacting partners that may facilitate MERS-CoV binding and entry. An alternate, but interesting approach led $\mathrm{Xia}$ et al. to identify peptides that can inhibit MERS-CoV fusion by studying the bat HKU4 coronavirus. The authors identified inhibitory peptides in the HR2 domain of the HKU4 spike protein. These peptides were able to significantly inhibit MERS-CoV-mediated cell-cell fusion and viral infection in human cells [52]. We have also shown that MERS$\mathrm{CoV}$ (EMC/2012 strain) cannot inhibit antiviral responses in insectivorous bat cells, unlike human cells where wild-type virus can efficiently inhibit these responses [55]. Future studies exploring the antiviral adaptations in bats and camelid reservoir species may enable us to identify better therapeutic targets in spillover mammals, such as humans.

While attempts are ongoing to develop vaccines and therapeutics for humans, considerable progress is being made to develop a vaccine for camels. Since MERS-CoV transmission has been primarily documented from camels to humans, it is of interest to develop a vaccine to inhibit virus replication in camels that would limit the cycle of transmission. A recent study provides promising data for an adjuvanted MERS-CoV spike protein subunit vaccine that confers complete protection from MERS-CoV disease in alpaca and results in reduced and 


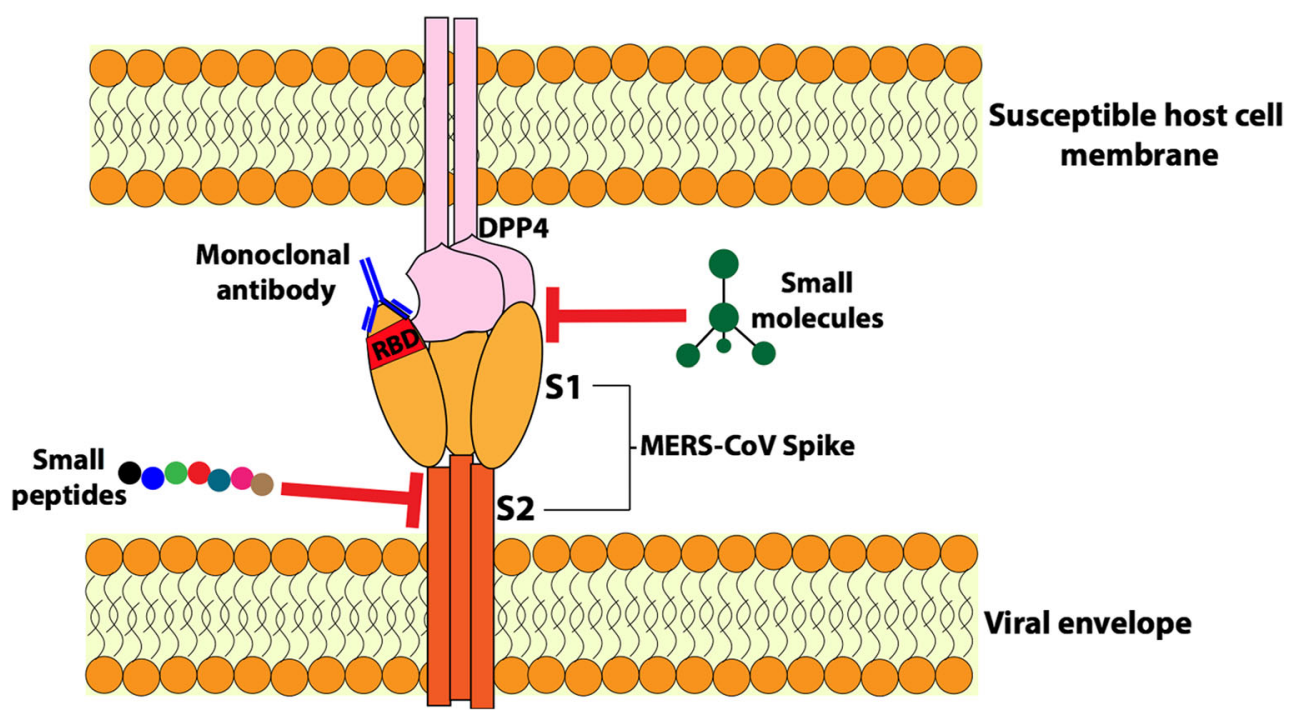

Fig. 3 Therapeutic approaches to disrupt MERS-CoV spike (S) protein and DPP4 interaction. MERS-CoV binds to its cellular receptor, dipeptidyl peptidase 4 (DPP4), via the receptor-binding domain (RBD) in the S1 subunit of the S protein. Following these interactions, the S2 subunit facilitates the fusion of viral and cellular membranes to release the

delayed viral shedding in the upper airways of dromedary camels [56]. Other relevant advances in developing MERS$\mathrm{CoV}$ vaccines have been reviewed here [50].

\section{Conclusion}

MERS-CoV is an emerging pathogen that necessitates immediate research to develop therapeutics and vaccine candidates. Unlike SARS-CoV, MERS-CoV has not emerged to spread and cause a global pandemic, yet. We risk the emergence of an efficient human-to-human transmissible strain unless we develop intervention strategies for the current circulating strains of MERS-CoV.

The lack of resources and the need for high containment labs have hindered our attempts to study this virus. There is a need to isolate other strains of MERS-CoV to determine variations in the circulating strains and associated pathogenesis. The correlates of protection in surviving patients are not well defined, but early intervention seems to offer some protection. However, it is easy to confuse early symptoms of MERS with that of the common cold. We need to establish a public communication strategy and prioritize patients that have had known contacts with camels.

In an observation study, combination treatment with interferon-beta and ribavirin was identified to be effective in early-stage patients but not in patients who were diagnosed late [57]. An ongoing clinical trial is studying the efficacy of interferon and antiviral combination treatments in MERS-CoV infected patients [58]. These studies will shed more light on possible ways to treat MERS patients. virus particle inside the cell. Monoclonal antibodies and small molecules directed against the RBD of the S1 subunit are being developed to disrupt the interaction between DPP4 and MERS-CoV S protein. In addition, small peptides are being developed to inhibit the membrane fusion activity of the S2 subunit of MERS-CoV S protein

In the meantime, ongoing research is identifying several novel strategies to inhibit MERS-CoV entry and replication in cells. Thus, in the future, it might be possible to use these experimental treatment options, in combination or alone, to prevent the onset of severe disease in patients that have likely been exposed to MERS-CoV. However, the timing of the treatment will be crucial and it will be essential to identify patients during the early stages of infection. This further emphasizes the need for effective differential diagnostics and appropriate training of healthcare professionals. Vaccines for coronaviruses have been challenging to develop due to the ability of coronaviruses to recombine [59] and the possibility of exacerbating disease symptoms post an immune challenge $[60,61]$. However, subunit vaccines using the spike protein have generated promising results in Camelids and may one day be suitable for human-use, although not in the near future.

Funding $\mathrm{AB}$ is supported by a Michael G. DeGroote Fellowship. KM is supported by operating grants from the Canadian Institute for Health Research (CIHR) and the Natural Sciences and Engineering Research Council (NSERC) of Canada.

\section{Compliance With Ethical Standards}

Conflict of Interest Arinjay Banerjee and Karen Mossman each report that their lab is studying MERS-CoV and associated innate immune signaling in bat cells.

Kaushal Baid declares no potential conflicts of interest.

Human and Animal Rights and Informed Consent This article does not contain any studies with human or animal subjects performed by any of the authors. 


\section{References}

Papers of particular interest, published recently, have been highlighted as:

- Of importance

•- Of major importance

1. Hamre D, Procknow JJ. A new virus isolated from the human respiratory tract. Proc Soc Exp Biol Med. 1966;121(1):190-3.

2. McIntosh K, Dees JH, Becker WB, Kapikian AZ, Chanock RM. Recovery in tracheal organ cultures of novel viruses from patients with respiratory disease. Proc Natl Acad Sci U S A. 1967;57(4): 933-40.

3. CDC. Severe acute respiratory syndrome. 2004. https://www.cdc. gov/sars/about/fs-sars.html. Accessed February 202019.

4. Li W, Shi Z, Yu M, Ren W, Smith C, Epstein JH, et al. Bats are natural reservoirs of SARS-like coronaviruses. Science. 2005;310(5748):676-9. https://doi.org/10.1126/science.1118391.

5. Ge XY, Li JL, Yang XL, Chmura AA, Zhu G, Epstein JH, et al. Isolation and characterization of a bat SARS-like coronavirus that uses the ACE2 receptor. Nature. 2013;503(7477):535-8. https:// doi.org/10.1038/nature12711.

6. Graham RL, Baric RS. Recombination, reservoirs, and the modular spike: mechanisms of coronavirus cross-species transmission. $\mathrm{J}$ Virol. 2010;84(7):3134-46. https://doi.org/10.1128/JVI.01394-09.

7. Lau SK, Woo PC, Li KS, Huang Y, Tsoi HW, Wong BH, et al. Severe acute respiratory syndrome coronavirus-like virus in Chinese horseshoe bats. Proc Natl Acad Sci U S A. 2005;102(39):14040-5. https://doi.org/10.1073/pnas.0506735102.

8. Sharif-Yakan A, Kanj SS. Emergence of MERS-CoV in the Middle East: origins, transmission, treatment, and perspectives. PLoS Pathog. 2014;10(12):e1004457. https://doi.org/10.1371/journal. ppat.1004457.

9. Siu KL, Yeung ML, Kok KH, Yuen KS, Kew C, Lui PY, et al. Middle east respiratory syndrome coronavirus 4 a protein is a double-stranded RNA-binding protein that suppresses PACTinduced activation of RIG-I and MDA5 in the innate antiviral response. J Virol. 2014;88(9):4866-76. https://doi.org/10.1128/JVI. 03649-13.

10. Niemeyer D, Zillinger T, Muth D, Zielecki F, Horvath G, Suliman $\mathrm{T}$, et al. Middle East respiratory syndrome coronavirus accessory protein $4 \mathrm{a}$ is a type I interferon antagonist. J Virol. 2013;87(22): 12489-95. https://doi.org/10.1128/JVI.01845-13.

11. Yang Y, Zhang L, Geng H, Deng Y, Huang B, Guo Y, et al. The structural and accessory proteins $\mathrm{M}, \mathrm{ORF} 4 \mathrm{a}, \mathrm{ORF} 4 \mathrm{~b}$, and ORF 5 of Middle East respiratory syndrome coronavirus (MERS-CoV) are potent interferon antagonists. Protein Cell. 2013;4(12):951-61. https://doi.org/10.1007/s13238-013-3096-8.

12. Briese T, Mishra N, Jain K, Zalmout IS, Jabado OJ, Karesh WB, et al. Middle East respiratory syndrome coronavirus quasispecies that include homologues of human isolates revealed through wholegenome analysis and virus cultured from dromedary camels in Saudi Arabia. MBio. 2014;5(3):e01146-14. https://doi.org/10. 1128/mBio.01146-14.

13. Wang Q, Qi J, Yuan Y, Xuan Y, Han P, Wan Y, et al. Bat origins of MERS-CoV supported by bat coronavirus HKU4 usage of human receptor CD26. Cell Host Microbe. 2014;16(3):328-37. https://doi. org/10.1016/j.chom.2014.08.009.

14. Ithete NL, Stoffberg S, Corman VM, Cottontail VM, Richards LR, Schoeman MC, et al. Close relative of human Middle East respiratory syndrome coronavirus in bat, South Africa. Emerg Infect Dis. 2013;19(10):1697-9. https://doi.org/10.3201/eid1910.130946.

15. Moreno A, Lelli D, de Sabato L, Zaccaria G, Boni A, Sozzi E, et al. Detection and full genome characterization of two beta CoV viruses related to Middle East respiratory syndrome from bats in Italy. Virol J. 2017;14(1):239. https://doi.org/10.1186/s12985-017-0907-1.

16. Luo CM, Wang N, Yang XL, Liu HZ, Zhang W, Li B, et al. Discovery of novel bat coronaviruses in south China that use the same receptor as MERS coronavirus. J Virol. 2018. https://doi.org/ 10.1128/JVI.00116-18 This study discovered that spike protein from bat coronaviruses in China can bind to DPP4. This study further confirmed the role of bats as evolutionary hosts of MERS-CoV.

17. Anthony SJ, Gilardi K, Menachery VD, Goldstein T, Ssebide B, Mbabazi R, et al. Further evidence for bats as the evolutionary source of Middle East respiratory syndrome coronavirus. MBio. 2017;8(2). https://doi.org/10.1128/mBio.00373-17.

18. Memish ZA, Mishra N, Olival KJ, Fagbo SF, Kapoor V, Epstein JH, et al. Middle East respiratory syndrome coronavirus in bats, Saudi Arabia. Emerg Infect Dis. 2013;19(11):1819-23. https://doi.org/10. 3201/eid1911.131172.

19. Tao Y, Shi M, Chommanard C, Queen K, Zhang J, Markotter W, et al. Surveillance of bat coronaviruses in Kenya identifies relatives of human coronaviruses NL63 and 229E and their recombination history. J Virol. 2017;91(5). https://doi.org/10.1128/JVI.01953-16.

20. Farag E, Sikkema RS, Vinks T, Islam MM, Nour M, Al-Romaihi H, et al. Drivers of MERS-CoV emergence in Qatar. Viruses. 2018;11(1). https://doi.org/10.3390/v11010022.

21. Reusken CB, Messadi L, Feyisa A, Ularamu H, Godeke GJ, Danmarwa A, et al. Geographic distribution of MERS coronavirus among dromedary camels, Africa. Emerg Infect Dis. 2014;20(8): 1370-4. https://doi.org/10.3201/eid2008.140590.

22. Chastel C. Middle East respiratory syndrome (MERS): bats or dromedary, which of them is responsible? Bull Soc Pathol Exot. 2014;107(2):69-73. https://doi.org/10.1007/s13149-014-0333-1.

23. Assiri A, McGeer A, Perl TM, Price CS, Al Rabeeah AA, Cummings DA, et al. Hospital outbreak of Middle East respiratory syndrome coronavirus. N Engl J Med. 2013;369(5):407-16. https://doi.org/10.1056/NEJMoa1306742.

24. Hajjar SA, Memish ZA, McIntosh K. Middle East respiratory syndrome coronavirus (MERS-CoV): a perpetual challenge. Ann Saudi Med. 2013;33(5):427-36. https://doi.org/10.5144/02564947.2013.427.

25. Sawicki SG, Sawicki DL, Siddell SG. A contemporary view of coronavirus transcription. J Virol. 2007;81(1):20-9. https://doi. org/10.1128/JVI.01358-06.

26. Raj VS, Mou H, Smits SL, Dekkers DH, Muller MA, Dijkman R, et al. Dipeptidyl peptidase 4 is a functional receptor for the emerging human coronavirus-EMC. Nature. 2013;495(7440):251-4. https://doi.org/10.1038/nature12005.

27.• Letko M, Miazgowicz K, McMinn R, Seifert SN, Sola I, Enjuanes $\mathrm{L}$, et al. Adaptive evolution of MERS-CoV to species variation in DPP4. Cell Rep. 2018;24(7):1730-7. https://doi.org/10.1016/j. celrep.2018.07.045 This study identifies that the spike protein of MERS-CoV is capable of adapting to interact with DPP4 from different species to initiate cellular entry and replication.

28. Fehr AR, Perlman S. Coronaviruses: an overview of their replication and pathogenesis. Methods Mol Biol. 2015;1282:1-23. https:// doi.org/10.1007/978-1-4939-2438-7 1.

29. de Wit E, van Doremalen N, Falzarano D, Munster VJ. SARS and MERS: recent insights into emerging coronaviruses. Nat Rev Microbiol. 2016;14(8):523-34. https://doi.org/10.1038/nrmicro. 2016.81

30. Li W, Moore MJ, Vasilieva N, Sui J, Wong SK, Berne MA, et al. Angiotensin-converting enzyme 2 is a functional receptor for the SARS coronavirus. Nature. 2003;426(6965):450-4. https://doi.org/ 10.1038 /nature02145.

31. Perlman S, Netland J. Coronaviruses post-SARS: update on replication and pathogenesis. Nat Rev Microbiol. 2009;7(6):439-50. https://doi.org/10.1038/nrmicro2147. 
32. Sawicki SG, Sawicki DL, Younker D, Meyer Y, Thiel V, Stokes H, et al. Functional and genetic analysis of coronavirus replicasetranscriptase proteins. PLoS Pathog. 2005;1(4):e39. https://doi. org/10.1371/journal.ppat.0010039.

33. Ng DL, Al Hosani F, Keating MK, Gerber SI, Jones TL, Metcalfe MG, et al. Clinicopathologic, immunohistochemical, and ultrastructural findings of a fatal case of Middle East respiratory syndrome coronavirus infection in the United Arab Emirates, April 2014. Am J Pathol. 2016;186(3):652-8. https://doi.org/10.1016/j.ajpath.2015. 10.024 .

34. Walker DH. Value of autopsy emphasized in the case report of a single patient with Middle East respiratory syndrome. Am J Pathol. 2016;186(3):507-10. https://doi.org/10.1016/j.ajpath.2015.11.001.

35.• Lau SK, Lau CC, Chan KH, Li CP, Chen H, Jin DY, et al. Delayed induction of proinflammatory cytokines and suppression of innate antiviral response by the novel Middle East respiratory syndrome coronavirus: implications for pathogenesis and treatment. J Gen Virol. 2013;94(Pt 12):2679-90. https://doi.org/10.1099/vir.0. 055533-0. In this study, Lau et al. demonstrated for the first time that MERS-CoV induces a delayed inflammatory response ('cytokine storm'), which may contribute to its pathogenesis. The authors also confirm that MERS-CoV can attenuate the antiviral interferon response.

36. Menachery VD, Mitchell HD, Cockrell AS, Gralinski LE, Yount BL Jr, Graham RL, et al. MERS-CoV accessory ORFs play key role for infection and pathogenesis. MBio. 2017;8(4). https://doi.org/10. $1128 / \mathrm{mBio} .00665-17$. This study characterized the role of MERS-CoV accessory proteins. The authors identified the role of ORF5 and explored the option of using a ORF5 deletion MERS-CoV mutant as a live attenuated vaccine.

37. Janeway CA Jr, Medzhitov R. Innate immune recognition. Annu Rev Immunol. 2002;20:197-216. https://doi.org/10.1146/annurev. immunol.20.083001.084359.

38. Kawai T, Akira S. Innate immune recognition of viral infection. Nat Immunol. 2006;7(2):131-7. https://doi.org/10.1038/ni1303.

39. Koyama S, Ishii KJ, Coban C, Akira S. Innate immune response to viral infection. Cytokine. 2008;43(3):336-41. https://doi.org/10. 1016/j.cyto.2008.07.009.

40. Kok KH, Lui PY, Ng MH, Siu KL, Au SW, Jin DY. The doublestranded RNA-binding protein PACT functions as a cellular activator of RIG-I to facilitate innate antiviral response. Cell Host Microbe. 2011;9(4):299-309. https://doi.org/10.1016/j.chom. 2011.03.007.

41. Panne D, McWhirter SM, Maniatis T, Harrison SC. Interferon regulatory factor 3 is regulated by a dual phosphorylation-dependent switch. J Biol Chem. 2007;282(31):22816-22. https://doi.org/10. 1074/jbc.M703019200.

42.• Lui PY, Wong LY, Fung CL, Siu KL, Yeung ML, Yuen KS, et al. Middle East respiratory syndrome coronavirus M protein suppresses type I interferon expression through the inhibition of TBK1-dependent phosphorylation of IRF3. Emerg Microbes Infect. 2016;5:e39. https://doi.org/10.1038/emi.2016.33 This study identified the role of MERS-CoV M protein in suppressing innate antiviral responses in human cells. $M$ protein interacts with cellular kinase TBK1 and inhibits the phosphorylation of a key transcription factor, IRF3.

43. Canton J, Fehr AR, Fernandez-Delgado R, Gutierrez-Alvarez FJ, Sanchez-Aparicio MT, Garcia-Sastre A, et al. MERS-CoV 4b protein interferes with the NF-kappaB-dependent innate immune response during infection. PLoS Pathog. 2018;14(1):e1006838. https://doi.org/10.1371/journal.ppat.1006838 This study identified the role of MERS-CoV accessory protein $4 \mathrm{~b}$ in inhibiting NFKB-mediated innate immune response. ORF4b outcompetes NFKB for KPNA4 binding and translocation to the nucleus of the cell.
44. Lokugamage KG, Narayanan K, Nakagawa K, Terasaki K, Ramirez SI, Tseng CT, et al. Middle East respiratory syndrome coronavirus nspl inhibits host gene expression by selectively targeting mRNAs transcribed in the nucleus while sparing mRNAs of cytoplasmic origin. J Virol. 2015;89(21):10970-81. https://doi.org/10.1128/JVI.01352-15.

45. Ko JH, Muller MA, Seok H, Park GE, Lee JY, Cho SY, et al. Serologic responses of 42 MERS-coronavirus-infected patients according to the disease severity. Diagn Microbiol Infect Dis. 2017;89(2):106-11. https://doi.org/10.1016/j.diagmicrobio.2017. 07.006.

46. Choi JY, Oh JO, Ahn JY, Choi H, Kim JH, Seong H, et al. Absence of neutralizing activity in serum 1 year after successful treatment with antivirals and recovery from MERS in South Korea. Clin Exp Vaccine Res. 2019;8(1):86-8. https://doi.org/10.7774/cevr.2019.8. 1.86 .

47. Zhao J, Alshukairi AN, Baharoon SA, Ahmed WA, Bokhari AA, Nehdi AM, et al. Recovery from the Middle East respiratory syndrome is associated with antibody and T-cell responses. Sci Immunol. 2017;2(14). https://doi.org/10.1126/sciimmunol. aan5393.

48. Deng X, Hackbart M, Mettelman RC, O’Brien A, Mielech AM, Yi $\mathrm{G}$, et al. Coronavirus nonstructural protein 15 mediates evasion of dsRNA sensors and limits apoptosis in macrophages. Proc Natl Acad Sci U S A. 2017;114(21):E4251-E60. https://doi.org/10. 1073/pnas.1618310114.

49. Dorrington KJ. Properties of the Fc receptor on macrophages. Immunol Commun. 1976;5(4):263-80.

50. Zhou Y, Yang Y, Huang J, Jiang S, Du L. Advances in MERS-CoV vaccines and therapeutics based on the receptor-binding domain. Viruses. 2019;11(1). https://doi.org/10.3390/v11010060.

51. Liang R, Wang L, Zhang N, Deng X, Su M, Su Y, et al. Development of small-molecule MERS-CoV inhibitors. Viruses. 2018;10(12). https://doi.org/10.3390/v10120721.

52. Xia S, Lan Q, Pu J, Wang C, Liu Z, Xu W, et al. Potent MERS-CoV fusion inhibitory peptides identified from HR2 domain in spike protein of bat coronavirus HKU4. Viruses. 2019;11(1). https://doi. org/10.3390/v11010056.

53. Qian Z, Dominguez SR, Holmes KV. Role of the spike glycoprotein of human Middle East respiratory syndrome coronavirus (MERSCoV) in virus entry and syncytia formation. PLoS One. 2013;8(10): e76469. https://doi.org/10.1371/journal.pone.0076469.

54. Chu H, Chan CM, Zhang X, Wang Y, Yuan S, Zhou J, et al. Middle East respiratory syndrome coronavirus and bat coronavirus HKU9 both can utilize GRP78 for attachment onto host cells. J Biol Chem. 2018;293(30):11709-26. https://doi.org/10.1074/jbc.RA118. 001897.

55. Banerjee A, Falzarano D, Rapin N, Lew J, Misra V. Interferon regulatory factor 3-mediated signaling limits middle-east respiratory syndrome (MERS) coronavirus propagation in cells from an insectivorous bat. Viruses. 2019;11(2). https://doi.org/10.3390/ v11020152.

56. Adney D, Wang L, van Doremalen N, Shi W, Zhang Y, Kong W-P, et al. Efficacy of an adjuvanted Middle East respiratory syndrome coronavirus spike protein vaccine in dromedary camels and alpacas. Viruses. 2019;11(3). https://doi.org/10.3390/v11030212.

57. Al-Tawfiq JA, Momattin H, Dib J, Memish ZA. Ribavirin and interferon therapy in patients infected with the Middle East respiratory syndrome coronavirus: an observational study. Int J Infect Dis. 2014;20:42-6. https://doi.org/10.1016/j.ijid.2013.12.003.

58. Arabi YM, Alothman A, Balkhy HH, Al-Dawood A, AlJohani S, Al Harbi S, et al. Treatment of Middle East respiratory syndrome with a combination of lopinavir-ritonavir and interferon-betalb (MIRACLE trial): study protocol for a randomized controlled trial. Trials. 2018;19(1):81. https://doi.org/10.1186/s13063-017-2427-0. 
59. Su S, Wong G, Shi W, Liu J, Lai ACK, Zhou J, et al. Epidemiology, genetic recombination, and pathogenesis of coronaviruses. Trends Microbiol. 2016;24(6):490-502. https://doi.org/10.1016/j.tim. 2016.03.003.

60. Tseng CT, Sbrana E, Iwata-Yoshikawa N, Newman PC, Garron T, Atmar RL, et al. Immunization with SARS coronavirus vaccines leads to pulmonary immunopathology on challenge with the SARS virus. PLoS One. 2012;7(4):e35421. https://doi.org/10.1371/ journal.pone.0035421.

61. Bolles M, Deming D, Long K, Agnihothram S, Whitmore A, Ferris $\mathrm{M}$, et al. A double-inactivated severe acute respiratory syndrome coronavirus vaccine provides incomplete protection in mice and induces increased eosinophilic proinflammatory pulmonary response upon challenge. J Virol. 2011;85(23):12201-15. https:// doi.org/10.1128/JVI.06048-11.

Publisher's Note Springer Nature remains neutral with regard to jurisdictional claims in published maps and institutional affiliations. 